\title{
Student Support Systems for Undergraduate Medical Students During the COVID-19 Pandemic: A Systematic Narrative Review of the Literature
}

\section{Ali Ardekani}

Shiraz University of Medical Sciences

\section{Seyed Ali Hosseini}

Shiraz University of Medical Sciences

\section{Parinaz Tabari}

Shiraz University of Medical Sciences

\section{Zahra Rahimian}

Shiraz University of Medical Sciences

\section{Afrooz Feili}

Shiraz University of Medical Sciences

\section{Mitra Amini ( $\triangle$ mitraamini51@yahoo.com )}

Clinical Education Research Center, Shiraz University of Medical Sciences, Zand Avenue, Shiraz, Iran https://orcid.org/0000-0002-7332-5151

\section{Research article}

Keywords: medical education, mentors, COVID-19, medical students

Posted Date: November 3rd, 2020

DOl: https://doi.org/10.21203/rs.3.rs-99510/v1

License: (9) This work is licensed under a Creative Commons Attribution 4.0 International License. Read Full License

Version of Record: A version of this preprint was published at BMC Medical Education on June 22nd, 2021. See the published version at https://doi.org/10.1186/s12909-021-02791-9. 


\section{Abstract}

Background: The coronavirus disease 2019 (COVID-19) pandemic has boosted medical students' vulnerability to various problems. Given the stressful nature of medical disciplines, considerable attention must be paid to student support systems during pandemics. This study aimed to review the current literature regarding medical student support systems systematically.

Methods: We performed a systematic review of six databases and grey literature sources in addition to a hand search in the references of the articles in July 2020. We included all studies about support for undergraduate medical students delivered in response to the COVID-19 pandemic. In conducting this review, we used the Preferred Reporting Items for Systematic Reviews and Meta-Analyses (PRISMA) statement.

Results: A total of 5347 articles were retrieved from the databases, and 30 additional articles were extracted from other sources. After removing duplicates, we screened 3492 titles and abstracts according to our criteria. Among them, 51 full-text articles were assessed for eligibility, before seven studies were ultimately included for reviewal. We identified two major themes: (a) academic support and (b) mental health support.

Conclusion: There are several methods of supporting medical students while they are experiencing unprecedented changes in their educational trajectory. This review showed that, given the novel circumstances after the outbreak of COVID-19, the use of online student support methods had received more attention. Implications for further developments in student support systems in the time of the present pandemic were also discussed.

\section{Background}

Following the outbreak of the severe acute respiratory syndrome coronavirus 2 (SARS-CoV-2) in China, and the rapid spread of its consequent disease called COVID-19 worldwide, diverse social aspects of human life have been affected (1). As one of the most critical facets of social life, education has encountered many challenges considering its interactive nature (2). Meanwhile, medical education has faced plenty of issues due to the need for students to communicate with patients and, on the other hand, the responsibility of faculty staff to ensure the health of students, which is of paramount concern (3). Students' daily commute to teaching hospitals leads to the spread of the virus. Accordingly, the cancellation of instructional programs and the use of virtual teaching methods have been put on the agenda (4). Besides physical health concerns, the stressful nature of the medical disciplines exerts a great deal of psychological and social stress on students during their study period (5). Notably, medical trainees fighting the pandemic on the frontlines are under much psychological stress(6). All of the mentioned problems make it indispensable that medical students need academic and personal support to succeed during their training (7). The ultimate goal of student support systems is not merely to empower individuals in academic and clinical competencies but also to develop all aspects of a student's 
character as a whole (8). One way for students to adapt to new situations is to use a type of student support system called mentoring (9). The term 'mentor' was first mentioned in the ancient Greek legend of Homer as the name of a loyal confidant to Odysseus who took care of and taught his son Telemachus (10). In a systematic review in 2018, Akinla et al. concluded that near-peer mentoring programs for firstyear medical students are among the most effective methods of supporting them for professional and academic achievement (9).

Of course, it should be noted that supporting students is not limited to mentoring and includes a wide range of methods of support for student education, mental health, and even decision-making (8). Considering medical students' different learning styles in designing learning environments (11), employing cognitive-behavioral therapy (CBT) to reduce unhealthy perfectionism in medical students (12), and supporting professional identity formation in medical students (13) are some examples of student support systems. An integrated model consisting of dedicated counseling sessions for medical students, wellness group activities, online courses, and collaboration with student health services for referral (e.g., psychiatric counseling) is employed at Florida International University to reduce burnout and depression as byproducts of studying medicine (14). One study calls for developing stress management programs through training workshops to prevent mental health conditions in medical schools, given the high prevalence of such disturbances among medical students (15). Given the extra psychological burden that the current pandemic has put on medical students, student support systems' employment seems essential than ever before (16). Lessons learned from previous pandemics regarding these systems can be considered when devising the related programs (17). Recently, more attention has been directed toward supporting medical students because, in these unprecedented times, they are more vulnerable than ever before to a wide range of adversities (18).

The publication of articles after the outbreak of COVID-19 is growing (19). Studies introduce a diversity of new methods to support and educate students, also increasing in number. However, these methods need to be comprehensively reviewed before being utilized by medical schools in the unanticipated future. In the present study, we intended to do a comprehensive systematic review of the ways of supporting undergraduate medical students during the COVID-19 pandemic. It is hoped that by conducting this review study, the path of supporting students will be further paved.

\section{Methods}

In conducting this review, the Preferred Reporting Items for Systematic Reviews and Meta-Analyses (PRISMA) protocol was followed (20).

\section{Search Strategy}

In June 2020, the initial search was done to investigate suitable keywords and reach relevant results. The final search was conducted at the end of July 2020, using three clusters of words representing the "COVID-19 pandemic", "medical education," and "student support." Some other entry terms and synonyms 
were utilized, along with the mentioned keywords. PubMed, Embase, Scopus, Web of Science, ERIC databases, and Cochrane library were explored using word clusters and proper Boolean operators (AND, OR). Each database was investigated with an appropriate search strategy (Table 1). To access grey literature, the WorldCat database and the first 100 results of Google Scholar were included. Additionally, a hand search in the retrieved articles' reference list was performed. All citations were imported into EndNote X9 software (Clarivate Analytics, USA), and duplicates were removed. 
Table 1

Search strategies

\section{Database Search strategy}

PubMed ((coronavirus[MeSH Terms] or coronavirus[Title/Abstract] OR covid*[Title/Abstract] OR SARS-Cov-2*[Title/Abstract] OR 2019-nCoV*[Title/Abstract] OR 2019 novel coronavirus[Title/Abstract] OR coronavirus disease*[Title/Abstract])) AND (medical education[MeSH Terms] or medical education[Title/Abstract] or medical student*[MeSH Terms] or medical student*[Title/Abstract] or undergraduate medical education[MeSH Terms] or undergraduate medical education[Title/Abstract] or graduate medical education[MeSH Terms] or graduate medical education[Title/Abstract] medical school* [MeSH Terms] or medical school*[Title/Abstract] or (internship and residency[MeSH Terms]) or internship[Title/Abstract] or residen*[Title/Abstract] or clinical clerkship* [MeSH Terms] or clinical[Title/Abstract] or clerkship*[Title/Abstract] or education[MeSH Terms] OR educat*[Title/Abstract] or medicine[MeSH Terms] or medicine[Title/Abstract] or medical[Title/Abstract] or physician*[MeSH Terms] or physician*[Title/Abstract])) AND (mentor*[MeSH Terms] or mentor*[Title/Abstract] OR mentee*[Title/Abstract] OR coach*[Title/Abstract] OR counsel*[Title/Abstract] OR student* support[Title/Abstract] OR support system[Title/Abstract] OR peer[Title/Abstract] OR advis*[Title/Abstract] OR guide[Title/Abstract] OR confidant[Title/Abstract] OR consult*[Title/Abstract] OR cheerleader[Title/Abstract] OR trainer[Title/Abstract] OR tutor[Title/Abstract] OR helper[Title/Abstract] OR aid[Title/Abstract] OR director[Title/Abstract] OR instructor[Title/Abstract] OR guru[Title/Abstract] or "pastoral support"[Title/Abstract])

Embase ('coronavirus'/exp OR 'coronavirus' OR coronavirus:ab,ti OR covid*:ab,ti OR 'sars cov $2^{\star \prime}:$ ab,ti OR '2019 ncov*':ab,ti OR '2019 novel coronavirus':ab,ti OR 'coronavirus disease*':ab,ti) AND ('medical education'/exp OR 'medical education' OR 'medical student'/exp OR 'medical student' OR 'undergraduate medical education'/exp OR 'undergraduate medical education' OR 'undergraduate student'/exp OR 'undergraduate student' OR 'graduate medical education'/exp OR 'graduate medical education' OR 'medical school'/exp OR 'medical school' OR 'internship'/exp OR 'internship' OR 'residency education'/exp OR 'residency education' OR 'clinical education'/exp OR 'clinical education' OR 'medicine'/exp OR 'medicine' OR 'physician'/exp OR 'physician' OR 'medical education':ab,ti OR 'medical student':ab,ti OR 'undergraduate medical education':ab,ti OR 'graduate medical education':ab,ti OR 'medical school':ab,ti OR internship:ab,ti OR residen*:ab,ti OR clinical:ab,ti OR clerkship*:ab,ti OR 'educat*or medicine':ab,ti OR medical:ab,ti OR physician*:ab,ti) AND ('mentor'/exp OR 'mentor' OR 'mentoring'/exp OR 'mentoring' OR 'counseling'/exp OR 'counseling' OR 'peer group'/exp OR 'peer group' OR mentor*:ab,ti OR mentee*:ab,ti OR coach*:ab,ti OR counsel*:ab,ti OR 'student* support':ab,ti OR 'support system':ab,ti OR peer:ab,ti OR advis*:ab,ti OR guide:ab,ti OR confidant:ab,ti OR consult*:ab,ti OR cheerleader:ab,ti OR trainer:ab,ti OR tutor:ab,ti OR helper:ab,ti OR aid:ab,ti OR director:ab,ti OR instructor:ab,ti OR guru:ab,ti OR 'pastoral support':ab,ti)

Scopus ( INDEXTERMS ( "coronavirus") OR TITLE-ABS-KEY("coronavirus" or "covid*" OR "SARSCov-2*" OR "2019-nCoV*" or "2019 novel coronavirus*" or "coronavirus disease*")) AND (INDEXTERMS("medical education" OR "medical student*" OR "undergraduate medical education" OR "graduate medical education" OR "medical schoo|*" OR "internship and residency" OR "clinical clerkship*" OR "education" OR "medicine" OR "physician*" ) OR TITLE-ABS-KEY("medical education" OR "medical student*" OR "undergraduate medical education" OR "graduate medical education" OR "medical school*" OR "internship" OR "residen*" OR "clinical" OR " clerkship*" OR "educat*" OR "medicine" OR "physician*" OR "medical"))AND (INDEXTERMS ("mentor*" ) OR TITLEABS-KEY ("mentor*" or "mentee*" or "coach*" or "counsel*" or "student* support" or "support system" or "peer" or "advis*" or "guide" or "confidant" or "consult*" or "cheerleader" or "trainer" or "tutor" or "helper" or "aid" or "director" or "instructor" or "guru" or "pastoral support")) 


\begin{tabular}{|c|c|}
\hline Database & Search strategy \\
\hline $\begin{array}{l}\text { Web of } \\
\text { science }\end{array}$ & 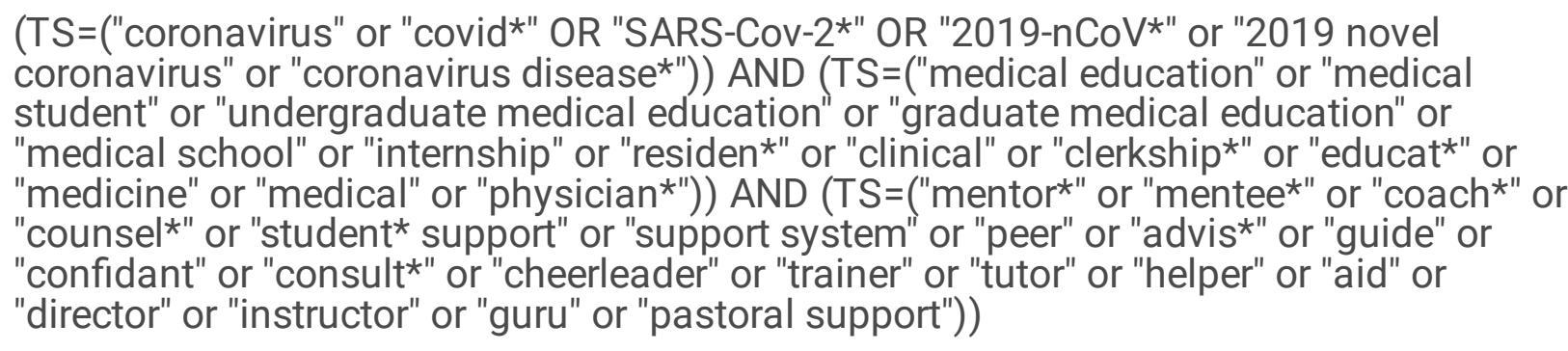 \\
\hline ERIC & $\begin{array}{l}\text { (coronavirus or covid* OR SARS-Cov-2 OR 2019-nCoV) AND (medical education or } \\
\text { medical student or undergraduate medical education or graduate medical education or } \\
\text { medical school or internship or residen }{ }^{\star} \text { or clinical or clerkship* or educat*or medicine or } \\
\text { medical or physician*) AND (mentor* or mentee* or coach* or counsel* or student* } \\
\text { support or support system or peer) }\end{array}$ \\
\hline Cochrane & 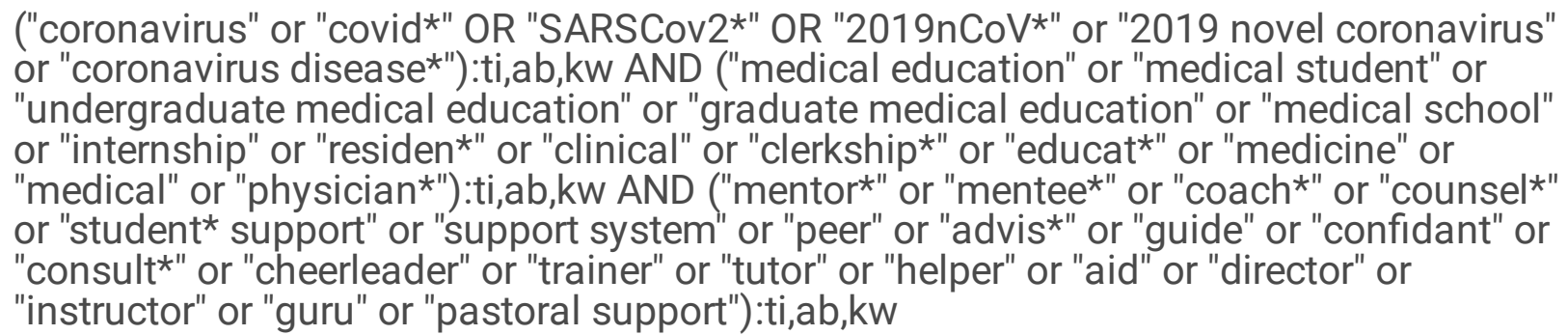 \\
\hline
\end{tabular}

\section{Study Selection}

This study aimed to review any kind of student support employed by medical universities in response to the unprecedented changes that arose from the pandemic. Titles and abstracts of all articles found were screened by A.A. and Z.R. independently. In the absence of an abstract, the full text of the study was used. The inclusion criteria were: studies that mentioned student support system programs in any stage of undergraduate medical education; articles published after 1st of December 2019; and studies describing student support systems explicitly used in response to the COVID-19 pandemic. The exclusion criteria were: opinion pieces and other studies involving no actual changes; studies that describe support systems that were not used in response to the COVID-19 pandemic; and articles that did not discuss support systems in undergraduate medical education. No exclusion occurred due to article language or country of publication. After initial screening, relevant articles were reached in full text and investigated by A.A. and P.T. independently for eligibility. In the process of screening, all disagreements between authors were solved by discussion or group consensus with a third party (M.A.).

\section{Data Extraction}

All eligible studies were reviewed by A.F. and SAH independently. Where there was a discrepancy between reviewers, the study was reviewed by the most expert author (MA), and a consensus was reached through discussion. Microsoft Excel (Microsoft, Redmond, WA, U.S.) spreadsheet was used for data collection. 
The studies were summarized according to the author, country of the project, the support system's goal, and an overview of the research.

\section{Critical Appraisal}

A checklist containing 11 items introduced by Buckley et al. (21) in 2009 was utilized to appraise the studies. If a study met seven criteria out of eleven, it was considered as a high-quality study. Although all studies were appraised precisely, none were excluded due to having low quality. P.T. and SAH appraised the studies independently; whenever there was a dispute, M.A. was consulted, and a consensus was reached.

\section{Results}

The database search yielded 5347 articles, consisting of 1022 in PubMed, 1513 in Embase, 1290 in Scopus, 467 in WOS, 36 in the Cochrane Library, 756 in ERIC, 163 in WorldCat, and 100 in Google Scholar. Also, 30 additional studies were included by a hand search in the references and relevant journals in the field of medical education (Fig. 1). All citations were imported into the EndNote software. After removing duplicates, 3492 titles and abstracts screened for the first time resulted in 51 relevant studies. The full texts of 51 articles were retrieved and screened. Finally, seven articles were found to be eligible. A summary of the findings is presented in Table 2.

Among the eligible studies, three were from the United Kingdom, two from Singapore, one from the United States, and one from Iran. Out of these studies, only Rastegar Kazerooni et al. (22) mentioned the sample size. Notably, all studies that were reviewed reported excellent outcomes of their programs. However, they only described their experience with innovating new support methods rather than comprehensively evaluating the outcomes. All of the included studies, at least in a part of their program, employed internetbased infrastructure for supporting students.

Table 2. Summary of the reviewed studies. 


\begin{tabular}{|c|c|c|c|}
\hline Author(s) & Country & Goal & What was done? \\
\hline $\begin{array}{l}\text { Ashokka } \\
\text { et al. (23) }\end{array}$ & Singapore & $\begin{array}{l}\text { To provide } \\
\text { students with } \\
\text { social, } \\
\text { educational, } \\
\text { emotional, and } \\
\text { material support. }\end{array}$ & $\begin{array}{l}\text { Support was provided to quarantined students } \\
\text { through volunteer groups, peer support systems, and } \\
\text { faculty staff, some of whom visited the student } \\
\text { dormitories while maintaining personal protection. } \\
\text { Both educational and emotional support was } \\
\text { provided, with relief packages also being dispensed } \\
\text { among the students. Online communication } \\
\text { platforms formed the basis of the majority of the } \\
\text { social support and teaching services. }\end{array}$ \\
\hline $\begin{array}{l}\text { Hodgson } \\
\text { \& Hagan. } \\
(24)\end{array}$ & $\begin{array}{l}\text { United } \\
\text { Kingdom }\end{array}$ & $\begin{array}{l}\text { To offer online } \\
\text { virtual support to } \\
\text { students. }\end{array}$ & $\begin{array}{l}\text { Student support groups were transitioned to a virtual } \\
\text { support system using the Microsoft Teams software } \\
\text { (Microsoft, Redmond, WA, U.S.) at two U.K. } \\
\text { universities during the COVID-19 pandemic. }\end{array}$ \\
\hline $\begin{array}{l}\text { Huddart } \\
\text { et al. (25) }\end{array}$ & $\begin{array}{l}\text { United } \\
\text { Kingdom }\end{array}$ & $\begin{array}{l}\text { To resolve } \\
\text { medical students' } \\
\text { ambiguity about } \\
\text { incoherent } \\
\text { information and } \\
\text { exhibit student } \\
\text { initiatives. }\end{array}$ & $\begin{array}{l}\text { The outcomes of a one-hour national Twitter-based } \\
\text { discussion on the uncertainties, concerns, and } \\
\text { initiatives of U.K. medical students concerning the } \\
\text { COVID-19 were presented. }\end{array}$ \\
\hline $\begin{array}{l}\text { Lee et al. } \\
\text { (26) }\end{array}$ & Singapore & $\begin{array}{l}\text { To provide } \\
\text { academic support } \\
\text { to medical } \\
\text { students, thereby } \\
\text { helping them } \\
\text { overcome } \\
\text { problems related } \\
\text { to new } \\
\text { educational } \\
\text { programs during } \\
\text { the COVID-19 } \\
\text { pandemic. }\end{array}$ & $\begin{array}{l}\text { A coaching program was devised using the master } \\
\text { adaptive learning (MAL) framework to build on } \\
\text { medical students' abilities and provide them with } \\
\text { much-needed support during the COVID-19 } \\
\text { pandemic. The framework consisted of the four } \\
\text { stages of planning, learning, assessing, and } \\
\text { adjusting. }\end{array}$ \\
\hline $\begin{array}{l}\text { Maini et } \\
\text { al. (27) }\end{array}$ & $\begin{array}{l}\text { United } \\
\text { Kingdom }\end{array}$ & $\begin{array}{l}\text { To promote } \\
\text { skillsets that help } \\
\text { manage the } \\
\text { personal and } \\
\text { emotional } \\
\text { challenges of } \\
\text { work, uncertainty, } \\
\text { and change. }\end{array}$ & $\begin{array}{l}\text { The authors discussed the launch of the freely } \\
\text { accessible short Massive Online Open Course } \\
\text { (MOOC) in 'Coaching skills for Learner-Centered } \\
\text { Conversations' by the Imperial College London on the } \\
\text { EdX platform. }\end{array}$ \\
\hline $\begin{array}{l}\text { Rastegar } \\
\text { Kazerooni } \\
\text { et al. (22) }\end{array}$ & Iran & $\begin{array}{l}\text { To improve } \\
\text { students' coping } \\
\text { skills and mental } \\
\text { preparedness in } \\
\text { the face of the } \\
\text { pandemic. }\end{array}$ & $\begin{array}{l}\text { Three hundred and seventy-one junior medical } \\
\text { students underwent near-peer mentoring by senior } \\
\text { students and expert faculty members using a social } \\
\text { media platform. }\end{array}$ \\
\hline
\end{tabular}




\begin{tabular}{|c|c|c|c|}
\hline Author(s) & Country & Goal & What was done? \\
\hline $\begin{array}{l}\text { Stetson et } \\
\text { al. (28) }\end{array}$ & USA & $\begin{array}{l}\text { To promote } \\
\text { professional } \\
\text { identity formation } \\
\text { and reduce } \\
\text { anxiety, fear, and } \\
\text { stress during the } \\
\text { COVID-19 } \\
\text { pandemic. }\end{array}$ & $\begin{array}{l}\text { The Zoom application (Zoom Video } \\
\text { Communications Inc., USA) was used to facilitate } \\
\text { small group-based guided reflection to promote } \\
\text { professional identity formation by mitigating anxiety, } \\
\text { fear, and stress among medical students of the San } \\
\text { Francisco School of Medicine. }\end{array}$ \\
\hline
\end{tabular}

\section{Discussion}

To date, we did not find any reviews focusing specifically on ways of supporting medical students during the COVID-19 pandemic. However, two reviews are available on medical education innovations in response to the pandemic. Dedeilia et al. (29) reviewed educational challenges and innovations in the medical context. In another research by Gordon et al. (30), medical education developments in response to the COVID-19 were reviewed. Although previous reviews were done with outstanding efforts, they did not precisely investigate support systems. Our review has no common citations with their reviews due to different selection criteria and rapid expansion of the literature.

The eligible studies can be categorized into two major themes:

a. Academic support to help medical students cope with new educational changes during the COVID-19 pandemic.

b. Mental health support for students during the COVID-19 pandemic.

\section{Academic support}

Two papers reported new adaptations to provide academic support to the medical students. In the study conducted by Huddart et al. (25), the outcomes of a one-hour national Twitter-based discussion on the uncertainties, concerns, and initiatives of U.K. medical students in relation to COVID-19 were presented. The discussion included 1586 tweets and was hosted by the Becoming a Doctor organization, which supports medical trainees. Some of the students' critical concerns included the fear of burnout, the necessity of adequate supervision, and the need for personal protective equipment. Furthermore, students shared uncertainty regarding whether they could obtain the required clinical skills through online learning systems. The initiatives discussed included clinical volunteering and non-clinical volunteer work like awareness campaigns and community members' assistance. Using a large-scale hashtag allowed the involved parties to connect with one another and provide relief to students in that the relevant authorities could hear their opinions. In a Singapore-based study directed by Lee et al. (26), a coaching program was devised using the master adaptive learning framework to build on medical students' abilities and provide them with much-needed support during the COVID-19 pandemic. The framework consisted of the four stages of planning, learning, assessing, and adjusting. The program involved both academic coaches, who tracked and analyzed the medical students' performance, examined their methods of studying and 
learning through regular 30-minute discussions, and faculty staff, who addressed the students' specific content-based needs. During academic coaching, the emphasis was on: (a) self-reflection; (b) specific, measurable, achievable, relevant, and time-based (SMART) goal setting; (c) the utilization of appropriate study plans including efficient learning techniques; and (d) self-care. The students found the program's proactive support highly helpful, with many acknowledging that the individualized goal-based studying strategies and short-interval follow-up sessions boosted their motivation, accountability, reflectiveness, and studying efficiency. Furthermore, coaches provided assistance when the students lost their motivation over time and found it challenging to adhere to their plans for studying; a holistic approach was employed that took into account the problems of the study plan as well as the mental wellbeing and self-care of the student. The program led to significant improvements in the students' academic performance besides providing them with an excellent support network during the troubling conditions.

\section{Mental Health Support}

Five papers discussed mental support for medical students. In the study of Rastegar Kazerooni et al. (22), a social media platform was established in Iran for near-peer mentoring during the COVID-19 pandemic. Ten senior medical students who had been thoroughly trained in peer mentoring were supervised by the medical education faculty staff in their efforts to mentor 371 juniors through the online platform. During discussions about the junior students' concerns and needs, several key recommendations were passed on by the senior peers, including stress management and relaxation, exercise, virtual contact with peers and family, and time management during the quarantine. According to a survey of the participants, the program positively impacted the professional growth of the juniors. It helped them to adjust to the unprecedented conditions. Nonetheless, the desire for non-virtual face to face consultations prevailed. Among the eligible studies, only in one study (22), peer mentoring as a support tool was evaluated. As mentioned in the previous reviews $(9,31)$, this method can be utilized as a tool for advancement in all aspects of a trainee's behavior.

In another study, the coordinated national responses of medical teaching institutions during the COVID-19 pandemic were discussed by Ashokka et al. (23), with a particular emphasis being placed on the need to sustain medical education. One central theme discussed was the enhancement of university support systems. Support was provided to quarantined students through volunteer groups, peer support systems, and faculty staff, some of whom visited the student dormitories while maintaining personal protection. Both educational and emotional support was provided, with relief packages also being dispensed among the students. Online communication platforms formed the basis of the majority of the social support and teaching services. Given the rapidly changing environment, a layered coaching and support system was used to guide students' responses.

Furthermore, each sub-cohort or clinical group of students had a leader for representation and coordination in the student network system. In this network, the plans for digital changes in the teaching environment, the students' expectations, the administrative requirements, the online code of conduct, and 
the support systems available were presented. Furthermore, students could send their inquiries, concerns, and ideas to the COVID-19 response team through a feedback system. By obtaining informal feedback from the parties involved, the researchers found that a smooth transition to online communication was made, though technical difficulties (e.g., poor internet bandwidth) and concerns regarding the need for real-life student-patient interactions were put forth by both students and staff.

In a related article, Stetson et al. (28) discussed their experience with the use of the Zoom application (Zoom Video Communications Inc., USA) to provide small, group-based, guided reflection sessions aimed at promoting professional identity formation (PIF) by mitigating anxiety, fear, and stress among medical students of the San Francisco School of Medicine during the COVID-19 pandemic. Previously existing small groups were transitioned to the web-based platform; faculty coaches and peers, many of whom were involved with care for COVID-19 patients, were included in the program. The researchers found that students were uncertain regarding their roles but were eager to help during the crisis, with feelings of isolation, helplessness, and fear being common. The opportunity for PIF during this troublesome state of emergency was relieving for most students, with the conscious reflection being made possible through virtual connection with their role models. The students felt that by allowing them to discuss their thoughts and emotions with their peers, the program reduced their isolation and normalized their reactions, ultimately reducing stress and anxiety.

In an article authored by Maini et al. (27), the researchers' experience with the launch of the freely accessible short Massive Online Open Course (MOOC) in 'Coaching skills for Learner-Centred Conversations' by the Imperial College London on the EdX platform was discussed. The program aimed at supporting students and educators both locally and globally, given the burden of the COVID-19 pandemic, promoting skillsets that help manage the personal and emotional challenges of work, uncertainty, and change. The virtual program facilitates person-centered conversions in clinical practice. It helps decrease burnout by allowing faculty members and students to comprehend and apply solutionoriented coaching skills. Such skills can be used in virtual patient visits, given the need for social distancing. However, this novel initiative is yet to be evaluated.

In another study, Hodgson and Hagan (24) described their experience with the transition of student support groups to a virtual support system using the Microsoft Teams software (Microsoft, Redmond, WA, U.S.) at two U.K. universities during the COVID-19 pandemic. Institutional subscriptions were obtained for the software, with free access to all students and staff via smartphones and computers. The software facilitated both one-to-one and group communication via video, audio, and text. The researchers reported that a smooth adaptation was made after simple instructions were given regarding how the platform was to be used. The staff found that the platform could bridge the gap between informal communications and formal meetings, with many of them not having had any similar engagement forms with students beforehand. A key finding was that the quality of the experience for both students and staff was enhanced when video calls were made instead of audio calls as the parties involved could have a better conversation when they could see one another. 
Furthermore, scheduled video calls were useful in maintaining an organized structure, which was essential for keeping a routine, maintaining wellbeing, and allowing the parties to understand and relate to the program. Positive feedback was also obtained regarding the group chat system, which allowed students to virtually connect with other members of their cohort in the unprecedented circumstances of social distancing in which anxiety and loneliness levels have increased due to social withdrawal. Student feedback indicated that this group chat function provided some relief in connecting with those facing similar experiences during the pandemic. The researchers reported that an increasing number of students joined the initiative since the start of the pandemic. Nonetheless, they acknowledged limitations that were encountered by some students, such as poor internet bandwidth and lack of the required information technology systems. To overcome these problems, students could use the $4 \mathrm{G}$ connection of their smartphones and apply for funding from their university for personal computer equipment, giving rise to a higher inclusivity rate.

Although online methods have been suggested in all studies, it should be borne in mind that using these methods cannot act as a panacea for plenty of problems that arise after the pandemic. It should not be forgotten that many clinical students are forced to attend rotations and live in dormitories. Supporting this group of students, not only psychologically but also in terms of facilities, is essential.

Our suggestions are: (a) needs assessment among students about their needs in this period should take place, (b) medical education specialists and faculty officials should plan to meet the identified needs, (c) investigating the impacts of the implemented programs to ensure its quality.

This study reviewed new ways to empower and support students during this challenging time. Considering that physical distancing is an effective method to prevent the spread of the disease, medical schools are forced to use online and virtual methods to support students (32). This sudden change in the way students are educated will undoubtedly give rise to many problems for universities. Therefore, the service delivery infrastructure in medical schools is bound to change. Further research should be done to determine novel ways of student support and assess their efficiency.

\section{Strengths And Limitations}

As described above, there are several ways of supporting students during these unprecedented times, and it is up to medical faculties around the world to support and empower their students. Despite extensive efforts, there are no comprehensive interventions with defined outcomes in the form of original articles available yet. However, the reviewed studies present valuable information for medical school authorities to employ different support systems for students during the unforeseeable future. The literature's infancy resulted in a lack of relevant articles and, consequently, the reduced number of included studies. It is essential to mention that all of the included studies suffered from a lack of presenting their programs' outcomes. Though, they were not recognized as low-quality studies according to the appraisal. This could be due to the rapid expansion of innovations. 


\section{Conclusion}

Although the time students spend in medical schools is a small part of a long journey of being a physician, significant professional and personal development could occur in these times. Medical students are vulnerable during the COVID-19 pandemic but, if adequately supported, can help combat this heavy burden imposed by the pandemic on healthcare organizations around the globe. Moreover, we all know that this will not be the last pandemic, so student support and training during the present outbreak can make a strong foundation to comprehend how to fight future instances. Taken together, the results of our review assert that methods of supporting medical students should be adapted to the new circumstances, and medical faculties should utilize virtual, online methods. Future studies should consider this as a basis for further developments.

\section{Abbreviations}

COVID-19

Coronavirus Disease 2019, SARS-CoV-2:Severe Acute Respiratory Syndrome Coronavirus 2, PIF:Professional Identity Formation

\section{Declarations}

\section{Acknowledgments}

This study is extracted from the thesis that was done by Ali Ardekani for obtaining a master's degree in medical education. This study was approved by the Deputy of Research, Shiraz University of Medical Sciences (Project number 23272).

\section{Authors' contributions}

All authors participated in designing the study, analyzing and interpreting the data. All authors were major contributors in writing the manuscript and approved the final manuscript.

\section{Competing interests}

Mitra Amini is the associate editor of the BMC Medical Education journal, but there is no competing interest to declare. The authors declare that they have no competing interests.

\section{Funding}

Not applicable.

\section{Availability of data and materials}

Not applicable. 


\section{Ethics approval and consent to participate}

Not applicable.

\section{Consent for publication}

Not applicable.

\section{References}

1. Chakraborty I, Maity P. COVID-19 outbreak: Migration, effects on society, global environment and prevention. Science of The Total Environment. 2020;728:138882.

2. Bao W. COVID-19 and online teaching in higher education: A case study of Peking University. Human Behavior and Emerging Technologies. 2020;2(2):113-5.

3. Rose S. Medical student education in the time of COVID-19. Jama. 2020.

4. Ahmed H, Allaf M, Elghazaly H. COVID-19 and medical education. The Lancet Infectious Diseases. 2020.

5. Dyrbye LN, Thomas MR, Shanafelt TD. Systematic review of depression, anxiety, and other indicators of psychological distress among U.S. and Canadian medical students. Acad Med. 2006;81(4):35473.

6. Li Y, Wang Y, Jiang J, Valdimarsdóttir UA, Fall K, Fang F, et al. Psychological distress among health professional students during the COVID-19 outbreak. Psychological Medicine. 2020:1-3.

7. Vogan CL, McKimm J, Da Silva AL, Grant A. Twelve tips for providing effective student support in undergraduate medical education. Medical teacher. 2014;36(6):480-5.

8. Sandars J, Patel R, Steele H, McAreavey M. Developmental student support in undergraduate medical education: AMEE Guide No. 92. Medical teacher. 2014;36(12):1015-26.

9. Akinla O, Hagan P, Atiomo W. A systematic review of the literature describing the outcomes of nearpeer mentoring programs for first year medical students. BMC medical education. 2018;18(1):98.

10. Ragins BR, Kram KE. The roots and meaning of mentoring. The handbook of mentoring at work: Theory, research, and practice. 2007:3-15.

11. McGowan J, Abrams M, Frank M, Bangert M. Creating a virtual community of learning predicated on medical student learning styles. AMIA Annu Symp Proc. 2003;2003:435-44.

12. Chand SP, Chibnall JT, Slavin SJ. Cognitive Behavioral Therapy for Maladaptive Perfectionism in Medical Students: A Preliminary Investigation. Acad Psychiatry. 2018;42(1):58-61.

13. Cruess RL, Cruess SR, Boudreau JD, Snell L, Steinert Y. Reframing medical education to support professional identity formation. Acad Med. 2014;89(11):1446-51.

14. Rivera-Rodriguez M, Shoua-Desmarais N. Case Report: The Gold Standard: The Case for Inclusion of a Medical Student-Specific Counseling Center and Wellness Programming in Early Medical Education. J Clin Psychol Med Settings. 2020. 
15. Huynh Q, Tanasugarn C, Kengganpanich M, Lapvongwatana P, Khuong L, Thai TT. Mental Well-being, and Coping Strategies during Stress for Preclinical Medical Students in Vietnam. Journal of Population and Social Studies. 2019;28:116-29.

16. Sartorao Filho Cl, Rodrigues WCdLV, de Castro RB, Marcal AA, Pavelqueires S, Takano L, et al. Impact of Covid-19 pandemic on mental health of Medical students: A cross-sectional study using GAD-7 and PHQ-9 questionnaires. medRxiv. 2020.

17. Maunder RG. Was SARS a mental health catastrophe? Gen Hosp Psychiatry. 2009;31(4):316-7.

18. Chandratre S. Medical Students and COVID-19: Challenges and Supportive Strategies. Journal of Medical Education and Curricular Development. 2020;7:2382120520935059.

19. Rada G, Verdugo-Paiva F, Ávila C, Morel-Marambio M, Bravo-Jeria R, Pesce F, et al. Evidence synthesis relevant to COVID-19: a protocol for multiple systematic reviews and overviews of systematic reviews. Medwave. 2020;20(3):e7868.

20. Moher D, Liberati A, Tetzlaff J, Altman DG, Group P. Preferred reporting items for systematic reviews and meta-analyses: the PRISMA statement. PLoS med. 2009;6(7):e1000097.

21. Buckley S, Coleman J, Davison I, Khan KS, Zamora J, Malick S, et al. The educational effects of portfolios on undergraduate student learning: a Best Evidence Medical Education (BEME) systematic review. BEME Guide No. 11. Medical teacher. 2009;31(4):282-98.

22. Rastegar Kazerooni A, Amini M, Tabari P, Moosavi M. Peer mentoring for medical students during COVID-19 pandemic via a social media platform. Medical education. 2020.

23. Ashokka B, Ong SY, Tay KH, Loh NHW, Gee CF, Samarasekera DD. Coordinated responses of academic medical centres to pandemics: Sustaining medical education during COVID-19. Med Teach. 2020;42(7):762-71.

24. Hodgson JC, Hagan P. Medical education adaptations during a pandemic: Transitioning to virtual student support. Medical Education. 2020;54(7):662-3.

25. Huddart D, Hirniak J, Sethi R, Hayer G, Dibblin C, Meghna Rao B, et al. \#MedStudentCovid: How social media is supporting students during COVID-19. Med Educ. 2020.

26. Lee ICJ, Koh H, Lai SH, Hwang NC. Academic coaching of medical students during the COVID-19 pandemic. Med Educ. 2020.

27. Maini A, Saravanan Y, Singh TA, Fyfe M. Coaching skills for medical education in a VUCA world. Med Teach. 2020:1-2.

28. Stetson GV, Kryzhanovskaya IV, Lomen-Hoerth C, Hauer KE. Professional identity formation in disorienting times. Med Educ. 2020;54(8):765-6.

29. Dedeilia A, Sotiropoulos MG, Hanrahan JG, Janga D, Dedeilias P, Sideris M. Medical and Surgical Education Challenges and Innovations in the COVID-19 Era: A Systematic Review. In Vivo. 2020;34(3 Suppl):1603-11.

30. Gordon M, Patricio M, Horne L, Muston A, Alston SR, Pammi M, et al. Developments in medical education in response to the COVID-19 pandemic: A rapid BEME systematic review: BEME Guide No. 
63. Medical Teacher. 2020:1-14.

31. Frei E, Stamm M, Buddeberg-Fischer B. Mentoring programs for medical students--a review of the PubMed literature 2000-2008. BMC Med Educ. 2010;10:32.

32. Tabari P, Amini M. Educational and psychological support for medical students during the COVID-19 outbreak. Medical Education.ahead of print DOI: 10.1111/medu.14376

\section{Figures}

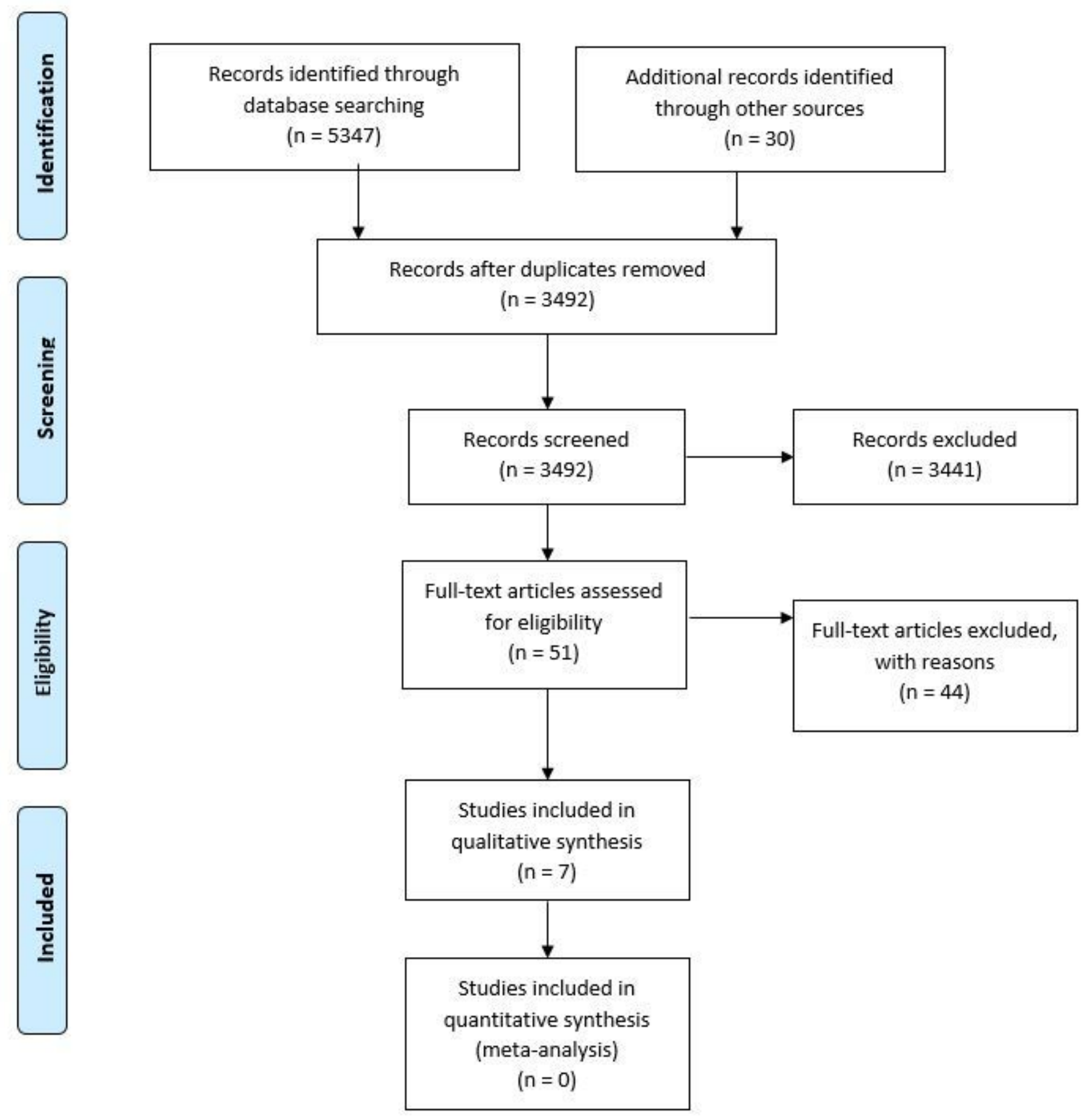


Figure 1

PRISMA flow-diagram for systematic review 